\title{
APLICAÇÃO DE REVESTIMENTOS COMESTÍVEIS EM PÊSSEGO (Prunus persica) ${ }^{1}$
}

\author{
Giselle de Assis JACOMETTI², Renata Fraxino de Almeida MENEGHEL ${ }^{2}$, Fábio YAMASHITA², *
}

\section{RESUMO}

O objetivo do trabalho foi avaliar a influência de revestimentos comestiveis sobre a vida-de-prateleira, perda de massa, atividade metabólica e contaminação microbiológicas em pêssegos in natura. Foram utilizados pêssegos brancos cv. Perola de Mairinque (IAC 769-8) revestidos com soluções de $1 \%$ de goma gelana $(\mathrm{p} / \mathrm{v})$ e $1 \%$ goma gelana $+1 \%$ sorbitol (p/v), embalados em caixas de papelão e armazenados a $10^{\circ} \mathrm{C} / 80-85 \%$ UR por 16 dias. Frutos sem revestimento serviram de controle. Os revestimentos à base de goma gelana e gelana+sorbitol não alteraram a atividade fisiológica dos pêssegos, medida através da taxa de respiração, teor de sólidos solúveis e acidez titulável ao longo da armazenagem. Não houve diferença entre as taxas de perda de massa, que ficaram em torno de $1,4 \mathrm{~g} / 100 \mathrm{~g}$.dia. Os revestimentos não alteraram a aceitação dos pêssegos em termos de sabor e em termos de aparência, o controle obteve notas superiores aos revestidos devida a opacidade que o revestimento conferiu aos frutos. Na contagem total de microrganismos aeróbios mesófilos e bolores e leveduras não houve diferença entre os tratamentos ao longo da armazenagem, mas em termos de microrganismos psicrotróficos os frutos revestidos apresentaram uma menor contagem em relação ao controle. Revestimentos à base de goma gelana e gelana+sorbitol não aumentaram a vida-de-prateleira de pêssegos armazenados sob refrigeração devido à composição do revestimento, que não reduziu a perda de massa nem a atividade fisiológica dos frutos.

Palavras-chave: vida-de-prateleira; frutas; armazenagem; fisiologia pós-colheita; contaminação microbiológica; perda de massa.

\section{SUMMARY}

USE OF EDIBLE COATING IN PEACHES. The objective of this work was to evaluate the influence of edible coatings on shelf-life, weight loss, metabolic activity and microbial contamination of peaches in natura. White peaches cv. Perola de Mairinque (IAC $769-8$ ) were coated with $1 \%$ gelan gum $(\mathrm{p} / \mathrm{v})$ and $1 \%$ gelan gum $+1 \%$ sorbitol $(\mathrm{p} / \mathrm{v})$ solutions, packed in paperboard box and stored at $10^{\circ} \mathrm{C} / 80-85 \%$ RH during 16 days. No coated fruits served as control. Gelan and gelan+sorbitol coatings had no effect on physiological activity of peaches, measured by respiration rates, total soluble solid content and total titratable acidity during storage. There was no difference among weight loss rates ( 1.4 g/ 100g.day) of all treatments. Edible coatings had no influence on flavor acceptance of the peaches but control fruits had higher scores than coated ones on appearance acceptance evaluation because the opacity caused by the coating. There was no difference among treatments in total count of aerobic mesophiles microorganisms and molds and yeasts during storage but for psychotropic microorganisms, coated fruits presented lower counts than control ones. Gelan and gelan+sorbitol based coatings have not extended shelf-life of cold stored peaches due to coating composition that did not reduced the weight loss and physiological metabolism of the fruits.

Keywords: shelf-life; fruits; storage; postharvest physiology; microbial contamination; weight loss.

\section{1 - INTRODUÇÃO}

Dentre os frutos de clima temperado, o pêssego é um dos mais pereciveis, em razão da sua alta atividade metabólica após a colheita e encontra-se entre as principais culturas de frutíferas nas regiões Sul e Sudeste do Brasil [6], sendo que a cultura do pêssego tende a crescer, com o plantio anual de mais de 500 mil mudas em todo o sul do país [17]. A produção nacional de pêssegos de mesa é insuficiente e a safra apresenta curta duração (8 semanas), faltando variedades precoces e tardias [4]. Em 1999, o Brasil importou US\$ 6 milhões em pêssegos e nectarinas [18].

Revestimentos comestiveis são finas camadas de material aplicados e formados diretamente na superficie do produto, sendo usados para substituir o revestimento de cera de proteção natural e para reduzir a perda de água de frutas e hortaliças $[8,13]$, e nem sempre podem substituir materiais de embalagem sintética não comes-

1. Recebido para publicação em 04/10/2001. Aceito para publicação em 15/05/2002.

2. UNIVERSIDADE ESTADUAL DE LONDRINA - Depto. Tecnologia de Alimentos e Medicamentos, Centro de Ciências Agrárias, C.P. 6001, CEP 86051-970, Londrina - PR. fabioy@uel.br - Tel (43) 371-4565 ramal 207 - Fax (43) 371-4080

* A quem a correspondência deve ser enviada. tivel, mas servem como adjunto para proporcionar maior qualidade, estendendo a vida-de-prateleira, possibilitando economia com materiais de embalagem [11].

A goma gelana é um agente formador de gel, obtido pelo processo de fermentação aeróbica pelo microrganismo Sphingomonas elodea, de cadeia linear formada por ácido glucurônico, glucose e raminose e forma géis a baixas concentrações $(0,05$ a $0,4 \%)$, tem boa estabilidade, é de fácil uso e possui excelente liberação de sabor e claridade [10]. O uso da gelana foi aprovado através da Portaria no 503, de 22 de junho de 1998 [16].

O objetivo do trabalho foi avaliar a influência de revestimentos comestiveis à base de goma gelana sobre a vida-de-prateleira, atividade metabólica, perda de massa e contaminação microbiológica de pêssegos in natura armazenados a $10^{\circ} \mathrm{C}$.

\section{2 - MATERIAL E MÉTODOS}

\section{1 - Material}

Foram utilizados pêssegos (Prunus persica L. Batsh) brancos da cultivar Pérola de Mairinque (IAC 769-8), no estádio firme maturo, com peso médio de $84,05 \pm 12,14 \mathrm{~g}$, produzidos na região de Londrina, PR, no período de 31 / $11 / 1999$ a $16 / 12 / 1999$. 
A goma utilizada para produção do revestimento comestivel foi a Gelana Kelcogel ${ }^{\circledR}$, produzida pela Monsanto do Brasil com tamanho de partícula de 42 mesh $(355 \mu \mathrm{m})$.

\section{2 - Preparo das amostras}

Os pêssegos foram submetidos a um tratamento fitossanitário, 30 minutos em solução de ácido acético $125 \mathrm{mg} / \mathrm{L}$ a $1^{\circ} \mathrm{C}$, que também serviu como préresfriamento. Posteriormente os pêssegos foram enxaguados em água corrente, secos à temperatura ambiente, pesados e divididos em três lotes, onde um deles serviu de controle ou testemunha e os outros lotes foram revestidos com duas soluções de goma. Os pêssegos foram embrulhados em papel de seda e embalados em caixas de papelão de $230 \mathrm{~mm} \times 210 \mathrm{~mm} \times 70 \mathrm{~mm}$, com quatro furos laterais, sendo que cada caixa continha 16 frutos. A seguir as caixas, 10 de cada tratamento, foram armazenados numa estufa para B.O.D. a $10^{\circ} \mathrm{C}$ com umidade relativa de $80-85 \%$.

\section{3 - Preparo e aplicação das soluções de goma gelana}

Foram testadas concentrações de 0,5, 0,75, 1 e 2\% de gelana $(\mathrm{p} / \mathrm{v})$ e $1 \%$ de plastificante (sorbitol e glicerol) (p/v) para produção da solução de goma, visando obter boa aderência, transparência e aparência do revestimento. As soluções foram preparadas com água destilada à temperatura ambiente, sob agitação constante com um agitador (Mix Wallita) e a adição do sorbitol ocorreu após completa dissolução da goma. Após a dissolução, a solução de goma foi aquecida até $70^{\circ} \mathrm{C}$ e resfriada até a temperatura ambiente. Os frutos foram totalmente submersos nas soluções por 30 segundos e dispostos em bancadas para escorrer o excesso de solução da goma e secar.

\section{4 - Análise microbiológica}

Foram feitas contagem total de microrganismos psicrotróficos, contagem padrão de aeróbicos mesófilos e contagem total de bolores e leveduras [2]. As amostras consistiram da homogeneização de três frutos escolhidos aleatoriamente (polpa e casca), onde $25 \mathrm{~g}$ foram adicionadas a $225 \mathrm{~mL}$ de água peptonada a $0,1 \%$, homogeneizadas em "Stomacher" (Modelo 400 - Inglaterra) por 120 segundos em velocidade alta. Foram feitas diluições $10^{-2}, 10^{-3}, 10^{-4}, 10^{-5}, 10^{-6}$ sob condições assépticas. Foram realizadas análises nos tempos $0,8 \mathrm{e}$ 16 dias de armazenagem a $10^{\circ} \mathrm{C}$, em duplicata.

\section{5 - Análises físico-químicas}

Tanto a acidez total titulável (\% de ácido cítrico) como o teor de sólidos solúveis totais ( $\left.{ }^{\circ} \mathrm{Brix}\right)$ dos frutos foram determinados de acordo com as Normas Analiticas do INSTITUTO ADOLFO LUTZ [9].

\section{6 - Vitamina C}

Foi utilizado o método padrão da AOAC [1] modificado por BENASSI \& ANTUNES [3]. Amostras de $25 \mathrm{~g}$ do fruto foram homogeneizadas com $50 \mathrm{~g}$ de solução de extração (ácido oxálico 2\%) com agitador (Mix Wallita) por dois minutos. Foi retirada uma alíquota de $20 \mathrm{~g}$ para diluição em $50 \mathrm{~mL}$ da solução extratora. Uma alíquota deste volume foi utilizada para titulação com 2,6-diclorofenolindofenol 0,01\% padronizado.

\section{7 - Taxa de perda de massa}

Os frutos foram pesados no início do experimento (massa inicial) e durante o armazenamento. A perda de massa foi calculada de acordo com a fórmula:

Perda de massa $(\mathrm{g} / 100 \mathrm{~g})=[($ massa inicial - massa final) /(massa inicial)] x 100

A partir dos dados foi feita uma correlação linear da perda de massa em função do tempo, de acordo com a seguinte equação:

Perda de massa $(\mathrm{g} / 100 \mathrm{~g})=\mathrm{C}+\mathrm{K}_{\mathrm{m}} \cdot \mathrm{t}$

$\mathrm{C}=$ constante $(\mathrm{g} / 100 \mathrm{~g})$

$\mathrm{K}_{\mathrm{m}}=$ taxa de perda de massa $(\mathrm{g} / 100 \mathrm{~g} \cdot$ dia)

$\mathrm{t}=$ tempo (dia)

\section{8 - Taxa de respiração}

O método de determinação da taxa de respiração foi baseado na capacidade de soluções básicas reagirem com o $\mathrm{CO}_{2}$, retendo-o em solução na forma de íon carbonato. Na Figura 1, temos o esquema geral do equipamento utilizado para a determinação da taxa de respiração do produto.

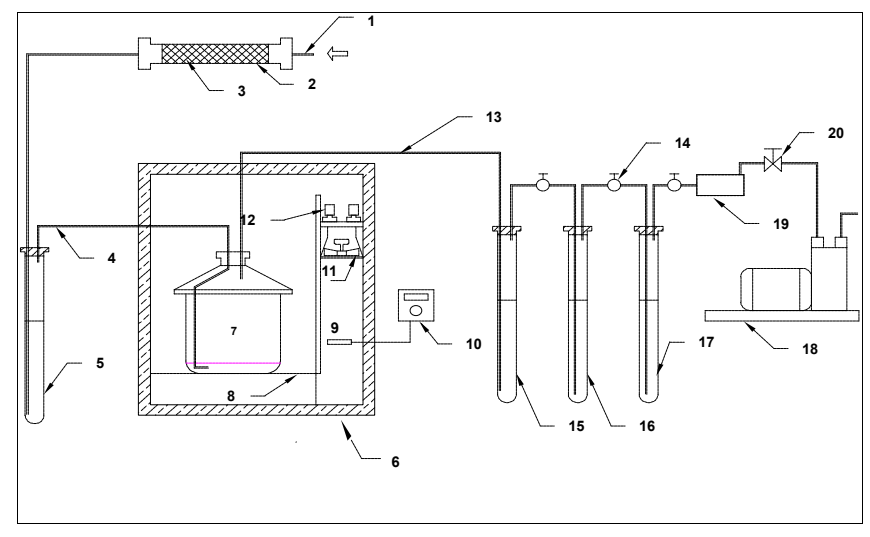

1. Entrada de ar 2. Tubo de vidro 3. Lã de vidro com $\mathrm{NaOH} 4$. Mangueira 5. Tubo de vidro com $\mathrm{NaOH}$ 6. Estufa para B.O.D. 7. Dessecador 8. Suporte 9. Bulbo do termostato 10. Termostato da estufa 11. Micro ventilador 12. Lâmpadas para aquecimento 13. Mangueira 14. Controle da vazão de ar 15. Tubo de vidro contendo $\mathrm{HCl} 16$. Tubo de vidro contendo $\mathrm{NaOH} 17$. Tubo de vidro reserva contendo $\mathrm{NaOH} 18$. Bomba aspiradora para circulação do ar 19. Recipiente de segurança 20. Válvula para controle do fluxo de ar

FIGURA 1. Esquema geral do equipamento para determinação da taxa de respiração

Neste sistema, o ar ambiente passa por um tubo contendo lã de vidro embebida em solução de $\mathrm{NaOH} 1 \mathrm{~N}$ e é posteriormente borbulhado em uma solução de $\mathrm{NaOH}$ $1 \mathrm{~N}$, para a retirada do $\mathrm{CO}_{2}$ presente. $\mathrm{O}$ ar, isento de $\mathrm{CO}_{2}$, percola pelos pêssegos $(\sim 2 \mathrm{~kg})$, mantidos dentro de um dessecador de $10 \mathrm{~L}$ mantido no interior de estufa para B.O.D. a $10^{\circ} \mathrm{C}$. O ar tem acesso pelo fundo do desseca- 
dor e é retirado pela parte superior. $\mathrm{O}$ ar aspirado do dessecador contendo $\mathrm{CO}_{2}$ e vapor de água, provenientes da respiração e transpiração do produto, é borbulhado em uma série de tubos contendo:

- solução de $\mathrm{HCl} 1 \mathrm{~N}$, que desumidifica o ar sem reter o $\mathrm{CO}_{2}$;

- solução de $\mathrm{NaOH} 1 \mathrm{~N}$, que absorve o $\mathrm{CO}_{2}$ presente no ar;

- solução de $\mathrm{NaOH} 1 \mathrm{~N}$, que absorve o possível $\mathrm{CO}_{2}$ residual não retido na solução anterior.

O procedimento utilizado para determinação da taxa de respiração foi o seguinte:

- padronização das soluções de $\mathrm{NaOH}$ e adição de um volume de $150 \mathrm{~mL}$ nos tubos pelos quais o ar era borbulhado;

- pesagem dos frutos e sua distribuição no dessecador;

- operação da bomba aspiradora com registro do período;

- após aproximadamente 24 horas foram retiradas alíquotas de $1 \mathrm{~mL}$ dos tubos contendo solução de $\mathrm{NaOH}$ e pipetadas em frascos Erlenmeyer com $10 \mathrm{~mL}$ de uma solução de $3 \%$ de cloreto de bário, sendo esta operação feita em duplicata. Como a reação de $\mathrm{CO}_{2}$ com $\mathrm{NaOH}$ é reversivel, a função do cloreto de bário foi a de formar carbonato de bário, que precipitou, evitando a saída de $\mathrm{CO}_{2}$;

- foram adicionadas 2 gotas de indicador fenolftaleína no frasco Erlenmeyer e as alíquotas tituladas com uma solução previamente padronizada de $\mathrm{HCl}$ 0,1N até o ponto de viragem;

- com o volume gasto de $\mathrm{HCl}$ determinou-se, através de um cálculo estequiométrico, a massa de $\mathrm{CO}_{2}$ liberada pelo produto após 24 horas. O resultado foi expresso em $\mathrm{mg}$ de $\mathrm{CO}_{2} / \mathrm{kg}$ de produto.h e calculado da seguinte forma:

$\mathrm{MCO}_{2}=\frac{22 \cdot N_{H C l} \cdot V_{T U B O} \cdot\left(V_{H C l F n}-V_{H C l F n+1}\right)}{V_{A L I Q U O T A}}$

$\mathrm{MCO}_{2}=\mathrm{MCO}_{2 \text { TUво } 1}+\mathrm{MCO}_{2 \text { тUво } 2}$

Taxa de Respiração $=\frac{M C O_{2}}{t \cdot\left(M_{\text {FRUTOS }}\right)}$

$\mathrm{MCO}_{2}=$ Massa de gás carbônico (mg CO

$\mathrm{N}_{\mathrm{HCl}}=$ Normalidade do $\mathrm{HCl}$ utilizado na titulação da alíquota

$\mathrm{V}_{\text {тUво }}=$ Volume de $\mathrm{NaOH}$ restante no tubo de onde retirou-se a alíquota $(\mathrm{mL})$

$\mathrm{V}_{\mathrm{HCl} \mathrm{Fn}}=$ Volume de $\mathrm{HCl}$ gasto na titulação da alíquota retirada no tempo anterior $(\mathrm{mL})$

$\mathrm{V}_{\mathrm{HCl} \mathrm{Fn}+1}=$ Volume de $\mathrm{HCl}$ gasto na titulação da alíquota retirada no dia $(\mathrm{mL})$ $\mathrm{t}=$ Tempo decorrido entre a última retirada de alíquota e a do dia (h)

$\mathrm{M}_{\mathrm{FRUTOS}}=$ Massa dos frutos colocados no dessecador (kg)

Todo o dispositivo foi mantido estanque, não permitindo vazamentos. Testes de vazamento e capacidade de retenção de $\mathrm{CO}_{2}$ foram realizados colocando-se um béquer contendo uma massa conhecida (balanças analítica) de $\mathrm{CaCO}_{3}(\sim 0,5 \mathrm{~g})$, previamente seca em estufa a $105^{\circ} \mathrm{C}$ por 2 horas, no interior do dessecador. Todo o sistema foi ligado por 2 horas para retirada do $\mathrm{CO}_{2}$ residual presente. Através de uma seringa foi injetado $25 \mathrm{~mL}$ de solução $\mathrm{HCl}$ $1 \mathrm{~N}$ no béquer. $\mathrm{O} \mathrm{CaCO}_{3}$ reagiu com $\mathrm{HCl}$ em excesso, produzindo $\mathrm{CO}_{2}+\mathrm{CaCl}_{2}+\mathrm{H}_{2} \mathrm{O}$. O sistema ficou ligado por 1 hora e após esse período foi feito o cálculo do $\mathrm{CO}_{2}$ recuperado. Houve uma recuperação de $96,4 \pm 1,2 \%$ (triplicata), um valor satisfatório tendo em vista que a reação do $\mathrm{CaCO}_{3}$ com $\mathrm{HCl}$ é rápida e o volume de $\mathrm{CO}_{2}$ gerado é bem superior ao da respiração de frutas.

\section{9 - Análise sensorial}

A aceitação dos pêssegos em função do sabor e da aparência foi avaliada ao longo do período de armazenagem. As amostras foram selecionadas aleatoriamente e os testes realizados no Laboratório de Análise Sensorial em cabines com luz branca. Em cada tempo de armazenagem, um grupo de 30 provadores não-treinados, consumidores do produto, avaliavam o quanto gostavam do sabor e da aparência do produto, através de uma escala hedônica não estruturada de 9 centímetros $(0=$ desgostei muitíssimo, 9=gostei muitíssimo). Os pêssegos, para a avaliação de aceitação em função do sabor, foram cortados em seis partes iguais no sentido longitudinal, sendo sido servida uma fatia, em prato plástico descartável. Cada provador avaliava uma amostra por vez, num máximo de 5 amostras por sessão. A avaliação de aceitação com relação à aparência foi feita fora das cabines, novamente num máximo de 5 amostras por sessão. A aparência dos pêssegos foi julgada utilizando-se os frutos inteiros, expostos sobre bancada e iluminadas com luz natural e fluorescente.

\subsection{0 - Análise estatística}

Para comparação da avaliação sensorial de aceitação, teor de vitamina $\mathrm{C}$, acidez titulável e contagem de microrganismos entre os diferentes tratamentos foram feitas análises de variância e aplicou-se o Teste de Tukey, para avaliar diferença entre as médias, utilizando o módulo ANOVA/MANOVA do programa Statistica ${ }^{\circledR}$ [19]. Correlações lineares foram calculadas entre o tempo de armazenagem e a perda de massa do produto, com os respectivos niveis de significância (p) e coeficientes de determinação $\left(\mathrm{R}^{2}\right)$, utilizando-se o módulo Multiple Regression do programa Statistica ${ }^{\circledR}[19]$.

\section{3 - RESULTADOS E DISCUSSÃO}

Foram testadas concentrações de $0,5 \% ; 0,75 \% ; 1 \%$ e $2 \%$ de goma gelana, para formação de revestimentos comestiveis em pêssegos, sendo que concentrações de 
0,5\% não aderiram bem à superficie do fruto e de 1 e $2 \%$ deram uma aparência opaca ao fruto. As soluções de goma gelana foram feitas por dissolução em água fria e também aquecendo até $70^{\circ} \mathrm{C}$, após a dissolução, sendo que com aquecimento os revestimentos ficaram mais transparentes e de melhor aparência.

Para melhorar a aparência e a flexibilidade do revestimento, foram testados os plastificantes glicerol e sorbitol com concentração de $1 \%$. O sorbitol proporcionou melhor aderência do revestimento sobre o fruto além de ter, segundo GARCIA, MARTINO \& ZARITZKY [7] e McHUGH, AUJARD \& KROCHTA [15], menor permeabilidade ao vapor de água quando comparado com glicerol. Foram testadas aplicações do revestimento à temperatura ambiente por borrifamento, pincelamento e imersão, sendo que esta última mostrou-se mais eficiente.

Desta forma os pêssegos foram revestidos com solução de gelana a 0,75\% (tratamento G) e com solução de gelana a $0,75 \%+1 \%$ de sorbitol (tratamento GS) e armazenados a $10^{\circ} \mathrm{C}$, pois de acordo com a literatura [14] essa temperatura não provoca injúria em pêssegos e é também a temperatura média utilizada em gôndolas refrigeradas em supermercados.

\section{1 - Análises físico-químicas}

As análises físico-químicas foram realizadas no inicio da armazenagem e após 3, 7, 10, 14 e 16 dias. O teor de sólidos solúveis totais inicial foi de $16,5 \pm 0,4^{\circ}$ Brix e para o fruto controle maduro, o teor máximo foi de $18,5 \pm 0,1^{\circ}$ Brix após 7 dias e para os frutos do tratamen-

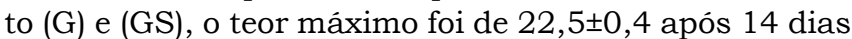
e $22,5 \pm 0,1^{\circ}$ Brix após 10 dias, respectivamente. Após estes tempos os valores apresentaram uma oscilação, provavelmente devido à variabilidade da matéria-prima.

Em relação ao $\mathrm{pH}$, os valores mantiveram-se praticamente constantes do início ao término do período de armazenamento, para todos frutos, com valores de 3,8 $\pm 0,1$.

$\mathrm{O}$ teor de vitamina $\mathrm{C}$ (Tabela 1 ) dos frutos variou de $12,4 \pm 0,1$ até $22,4 \pm 0,8 \mathrm{mg}$ vit.C/ $100 \mathrm{~g}$, podendo o pêssego ser considerado uma fonte razoável deste nutriente, uma vez que a necessidade diária recomendada é de $60 \mathrm{mg} /$ dia [5]. As diferenças de teores entre os tratamentos ao longo da armazenagem ocorreram, provavelmente, devido à variabilidade das amostras.

A acidez total titulável dos pêssegos diminuiu até o 7을 dia de armazenagem, ocorrendo um aumento gradual até o $16^{\circ}$ dia, sendo este comportamento observado para todos os tratamentos (Tabela 1). De acordo com LILL, O'DONOGHUE \& KING [14] e COELHO [6], a acidez dos pêssegos declina com o amadurecimento e armazenamento refrigerado, mas não foram encontradas referências que expliquem uma redução e posterior aumento da acidez, que pode ter ocorrido devido à perda de massa ao longo da armazenagem e conseqüente aumento na concentração dos ácidos. Os valores obtidos para essa cultivar são similares aos obtidos por KLUGE et al. [12], quando pêssegos da cv. 'Flordaprince' foram armazenados por 14 e 28 dias em embalagens plásticas.
TABELA 1. Teor de vitamina $\mathrm{C}$ e acidez titulável de pêssegos cv. Pérola de Mairinque com e sem revestimento durante armazenagem a $10^{\circ} \mathrm{C}$

\begin{tabular}{ccccc}
\hline ANÁLISE & $\begin{array}{c}\text { TEMPO } \\
\text { (dia) }\end{array}$ & CONTROLE REVESTIDO & $\begin{array}{c}\text { REVESTIDO } \\
\text { COM } \\
\text { GELANA }\end{array}$ & $\begin{array}{c}\text { COM } \\
\text { GELANA } \\
+ \text { SORBITOL }\end{array}$ \\
\hline & 0 & $20,9 \pm 1,3^{\mathrm{a}}$ & $20,9 \pm 1,3^{\mathrm{a}}$ & $20,9 \pm 1,3^{\mathrm{a}}$ \\
TEOR DE & 3 & $14,0 \pm 0,3^{\mathrm{b}}$ & $14,6 \pm 0,1^{\mathrm{b}}$ & $16,2 \pm 0,3^{\mathrm{a}}$ \\
VITAMINA C & 7 & $12,4 \pm 0,1^{\mathrm{c}}$ & $13,7 \pm 0,3^{\mathrm{b}}$ & $17,3 \pm 0,3^{\mathrm{a}}$ \\
(mg & 10 & $22,4 \pm 0,8^{\mathrm{a}}$ & $12,9 \pm 0,3^{\mathrm{b}}$ & $22,2 \pm 0,5^{\mathrm{a}}$ \\
vit.C/100g & 14 & $13,0 \pm 0,3^{\mathrm{c}}$ & $21,5 \pm 0,3^{\mathrm{a}}$ & $16,0 \pm 0,3^{\mathrm{b}}$ \\
de produto) & 16 & $22,1 \pm 0,1^{\mathrm{a}}$ & $19,1 \pm 0,1^{\mathrm{b}}$ & $22,1 \pm 0,1^{\mathrm{a}}$ \\
\hline & 0 & $0,44 \pm 0,03^{\mathrm{a}}$ & $0,44 \pm 0,03^{\mathrm{a}}$ & $0,44 \pm 0,03^{\mathrm{a}}$ \\
$\begin{array}{c}\text { ACIDEZ } \\
\text { TITULÁVEL }\end{array}$ & 3 & $0,39 \pm 0,01^{\mathrm{a}}$ & $0,42 \pm 0,33^{\mathrm{a}}$ & $0,42 \pm 0,06^{\mathrm{a}}$ \\
(\% de ácido & 10 & $0,31 \pm 0,04^{\mathrm{a}}$ & $0,27 \pm 0,05^{\mathrm{a}}$ & $0,31 \pm 0,01^{\mathrm{a}}$ \\
cítrico) & 14 & $0,30 \pm 0,01^{\mathrm{b}}$ & $0,34 \pm 0,03^{\mathrm{a}}$ & $0,33 \pm 0,01^{\mathrm{a}}$ \\
& 16 & $0,45 \pm 0,01^{\mathrm{a}}$ & $0,37 \pm 0,02^{\mathrm{a}}$ & $0,40 \pm 0,02^{\mathrm{a}}$ \\
& & $0,46 \pm 0,02^{\mathrm{a}}$ & $0,42 \pm 0,05^{\mathrm{a}}$ \\
\hline
\end{tabular}

a,b,c letras diferentes na mesma linha indicam que houve diferença significativa ao nivel de 0,05

Pelos resultados das análises físico-químicas durante o armazenamento, aparentemente não houve influência dos revestimentos sobre a atividade metabólica dos frutos de pêssego quando comparados com o controle.

\section{2 - Perda de massa}

Não houve diferença entre as taxas de perda de massa do controle e dos frutos revestidos com gelana (G) e gelana+sorbitol (GS) (Tabela 2), portanto os revestimentos não serviram de barreira à perda de água.

TABElA 2. Taxa de perda de massa de pêssegos cv. Pérola de Mairinque com e sem revestimento, armazenados a $10^{\circ} \mathrm{C}$, com valores de coeficiente de determinação $\left(R^{2}\right)$ e nível de significância do ajuste (p)

\begin{tabular}{cccc}
\hline TRATAMENTO & $\begin{array}{c}\text { TAXA DE PERDA DE MASSA } \\
\text { (g/100g de produto.dia) }\end{array}$ & $\mathrm{R}^{2}$ & $\mathrm{p}$ \\
\hline CONTROLE & $1,25 \pm 0,07^{\mathrm{a}}$ & 0,99 & $<0,01$ \\
GELANA & $1,48 \pm 0,07^{\mathrm{a}}$ & 1,00 & $<0,01$ \\
GELANA + SORBITOL & $1,42 \pm 0,04^{\mathrm{a}}$ & 1,00 & $<0,01$ \\
\hline
\end{tabular}

${ }^{a}$ letras iguais indicam que não houve diferença significativa ao nivel de 0,05

\section{3 - Taxa de respiração}

Os frutos controle atingiram uma taxa respiratória máxima de $67 \mathrm{mg} \mathrm{CO} / \mathrm{kg}$.h, após 14 dias de armazenagem, os revestidos com gelana (G) $76 \mathrm{mg}$ de $\mathrm{CO}_{2} / \mathrm{kg}$.h e os do tratamento gelana+sorbitol (GS) $65 \mathrm{mg} \mathrm{de} \mathrm{CO}_{2} / \mathrm{kg} . \mathrm{h}$, ambos após 16 dias (Figura 2). HARDENBURG (1971) apud COELHO [6], obteve valores de taxa respiratória de pêssegos de $5 ; 8 ; 38$ e $72 \mathrm{mg} \mathrm{CO} / \mathrm{kg}$.h a $0^{\circ} \mathrm{C} ; 4,4^{\circ} \mathrm{C} ; 5,6^{\circ} \mathrm{C}$ e $21,1^{\circ} \mathrm{C}$, respectivamente, que são semelhantes aos obtidos no presente trabalho. Os padrões respiratórios foram diferentes para cada um dos tratamentos, sendo que para os frutos controle o padrão se assemelha ao de frutos climatéricos, podendo ser observado um pico no 
$14^{\circ}$ dia. Os frutos revestidos apresentaram taxas de respiração menores que o controle do 10 ao $14^{\circ}$ dia de armazenagem, sendo que o tratamento G é o que reduziu de forma mais pronunciada essas taxas.

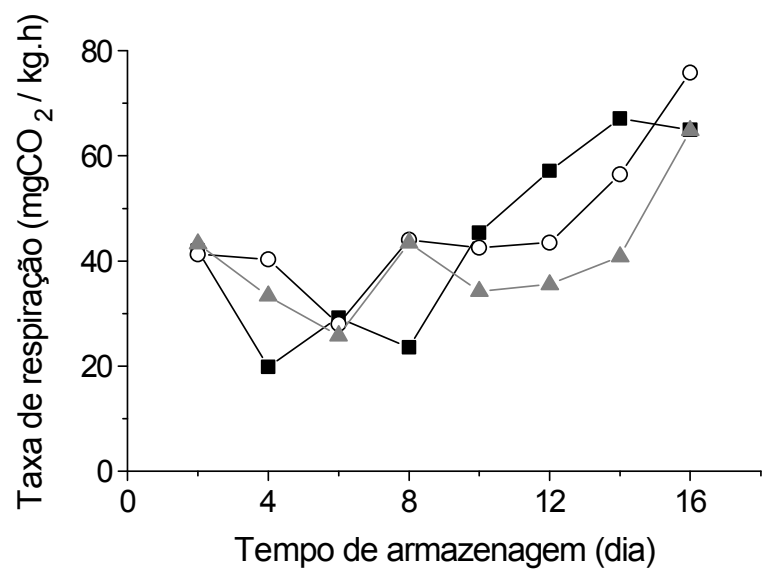

FIGURA 2. Taxa de respiração de pêssegos cv. Pérola de Mairinque revestidos com gelana $(\mathrm{O})$, gelana+sorbitol (s ) e sem revestimento $(n)$, armazenados a $10^{\circ} \mathrm{C}$.

\section{4 - Análise sensorial}

\subsection{1 - Aceitação de sabor}

Através de análise de variância e do teste de médias, verificou-se que não houve diferença entre as notas dos tratamentos para o mesmo tempo de armazenagem e, portanto, os revestimentos não interferiram na aceitação do sabor do fruto, nem apresentaram sabor residual (Tabela 3). As notas de todos os tratamentos foram diminuindo com o tempo de armazenagem, mas mantiveram-se superiores a 4,5 que foi a nota minima estabelecida para considerar o fruto apto para consumo. Após 14 dias de armazenagem, os frutos revestidos com gelana+sorbitol não foram servidos aos provadores por apresentarem contaminação microbiana visivel o mesmo ocorreu os frutos controle e os frutos revestidos com gelana após 16 dias de armazenagem.

TABELA 3. Valores médios resultantes da avaliação sensorial de sabor e aparência de pêssegos cv. Pérola de Mairinque revestidos e não revestidos armazenados a $10^{\circ} \mathrm{C}$ por $0,3,7,14 \mathrm{e}$ 16 dias ( 0 = desgostei muitíssimo, 9 = gostei muitíssimo).

\begin{tabular}{|c|c|c|c|c|}
\hline $\begin{array}{l}\text { AVALIAÇÃO } \\
\text { SENSORIAL }\end{array}$ & $\begin{array}{l}\text { TEMPO } \\
\text { (dia) }\end{array}$ & CONTROLE & $\begin{array}{c}\text { REVESTIDO } \\
\text { COM } \\
\text { GELANA }\end{array}$ & $\begin{array}{l}\text { REVESTIDO COM } \\
\text { GELANA+SORBITOL }\end{array}$ \\
\hline \multirow{5}{*}{ SABOR } & 0 & $8,02^{a}$ & $8,02^{a}$ & $8,02^{a}$ \\
\hline & 3 & $6,72^{a}$ & $5,66^{a}$ & $6,17^{a}$ \\
\hline & 7 & $5,57^{\mathrm{a}}$ & $5,20^{a}$ & $6,02^{a}$ \\
\hline & 14 & $5,07^{a}$ & $6,18^{a}$ & i.c. \\
\hline & 16 & i.c. & i.c. & i.c. \\
\hline \multirow{5}{*}{ APARÊNCIA } & 0 & $6,42^{a}$ & $6,42^{a}$ & $6,42^{a}$ \\
\hline & 3 & $7,12^{\mathrm{a}}$ & $3,68^{c}$ & $4,57^{b}$ \\
\hline & 7 & $7,32^{a}$ & $3,54^{\mathrm{c}}$ & $4,98^{b}$ \\
\hline & 14 & $4,14^{\mathrm{a}}$ & $2,62^{b}$ & $4,16^{a}$ \\
\hline & 16 & $3,61^{a}$ & $2,47^{b}$ & $1,92^{\mathrm{c}}$ \\
\hline
\end{tabular}

i.c. produto impróprio para consumo. $a, b, c$ letras diferentes na mesma linha indicam que houve diferença significativa ao nivel de 0,05 pelo teste de Tukey.

\subsection{2 - Aceitação de aparência}

Os frutos revestidos com gelana $(\mathrm{G})$ obtiveram, após três dias de armazenagem, nota média inferior a 4,5 e foram considerados impróprios para comercialização e, portanto, fora da sua vida-de-prateleira (Tabela 3). Já os frutos controle e os revestidos com gelana+sorbitol (GS) obtiveram notas médias superiores a 4,5 até o 7응 dia de armazenagem, sendo que as notas do controle neste período foram superiores às do tratamento GS. Após 14 dias de armazenagem, todos os frutos estavam impróprios para comercialização e é possível que a principal causa da rejeição tenha sido devido ao enrugamento, causado pela perda de massa. No caso dos frutos revestidos, a rejeição foi maior, pois com a perda de massa, os frutos diminuíram de volume e o revestimento ficou "solto", dando um aspecto opaco e pouco agradável ao fruto.

\section{5 - Análise microbiológica}

Os frutos apresentaram uma contagem inicial de

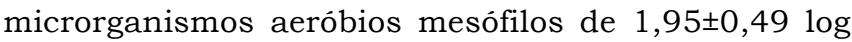
$\mathrm{UFC} / \mathrm{g}$ de fruto (Tabela 4). As contagens aumentaram em torno de 25 vezes, após a primeira semana de armazenamento, tanto para frutos revestidos com gelana (G) como para frutos controle e reduziram-se em torno de 4 vezes, após a segunda semana. Já os frutos revestidos com gelana e sorbitol (GS) apresentaram contagens 8 vezes maiores, após a primeira semana e 3 vezes maiores, após a segunda semana, porém não houve diferença significativa de contagem entre os frutos revestidos e não revestidos para os mesmos tempos de armazenagem.

Para microrganismos psicrotróficos a contagem inicial nos pêssegos foi de 4,10 $\pm 0,02 \mathrm{log} \mathrm{UFC} / \mathrm{g}$ e os frutos revestidos apresentaram, após duas semanas, contagens menores que os frutos controle (Tabela 4).

Com relação a bolores e leveduras a contagem inicial foi de 3,45 $\pm 0,64 \log \mathrm{UFC} / \mathrm{g}$ e foi aumentando para todos os tratamentos até o final do período de armazenamento (Tabela 4). Não se observou diferença entre o controle e os frutos revestidos para um mesmo tempo de armazenagem. De uma forma geral a utilização do revestimento não serviu de barreira contra o desenvolvimento microbiano, exceto para microrganismos psicrotróficos, mas também não favoreceu este desenvolvimento.

\section{4 - CONCLUSÕES}

Os revestimentos comestiveis à base de gelana e gelana+sorbitol não reduziram a perda de massa nem alteraram a atividade metabólica de pêssegos armazenados a $10^{\circ} \mathrm{C}$ quando comparados aos frutos sem revestimento. Devem ser feitos novos estudos com a incorporação de outras substâncias para diminuir a permeabilidade ao vapor de água, gás carbônico e oxigênio desses revestimentos para aumentar a vida-de-prateleira dos frutos. 
TABELA 4. Contagem total de microrganismos aeróbios mesófilos, psicrotróficos e bolores e leveduras em pêssegos cv. Pérola de Mairinque com e sem revestimento (controle), durante armazenagem a $10^{\circ} \mathrm{C}$

\begin{tabular}{ccccc}
\hline \multicolumn{5}{c}{$\begin{array}{c}\text { ANÁLISE MICROBIOLÓGICA DE PESSSEGOS } \\
\text { (log UFC/g de fruto) }\end{array}$} \\
\hline MICRORGANISMO & $\begin{array}{c}\text { TEMPO } \\
\text { (dia) }\end{array}$ & \multicolumn{4}{c}{$\begin{array}{c}\text { CONTROLE } \\
\text { GESIDO } \\
\text { GELANA }\end{array}$} & $\begin{array}{c}\text { REVESTIDO COM } \\
\text { GELANA+SORBITOL }\end{array}$ \\
\hline AERÓBIOS & 0 & $1,95 \pm 0,49^{\mathrm{a}}$ & $1,95 \pm 0,49^{\mathrm{a}}$ & $1,95 \pm 0,49^{\mathrm{a}}$ \\
MESÓFILOS & 8 & $3,33 \pm 0,01^{\mathrm{a}}$ & $3,35 \pm 0,04^{\mathrm{a}}$ & $2,87 \pm 0,24^{\mathrm{a}}$ \\
& 16 & $2,90 \pm 0,00^{\mathrm{a}}$ & $2,60 \pm 0,43^{\mathrm{a}}$ & $3,34 \pm 0,23^{\mathrm{a}}$ \\
\hline \multirow{3}{*}{ PSICROTRÓFICOS } & 0 & $4,10 \pm 0,02^{\mathrm{a}}$ & $4,10 \pm 0,02^{\mathrm{a}}$ & $4,10 \pm 0,02^{\mathrm{a}}$ \\
& 8 & $4,25 \pm 0,15^{\mathrm{a}}$ & $3,84 \pm 0,09^{\mathrm{a}}$ & $3,87 \pm 0,12^{\mathrm{a}}$ \\
& 16 & $4,70 \pm 0,00^{\mathrm{a}}$ & $4,22 \pm 0,06^{\mathrm{b}}$ & $3,94 \pm 0,14^{\mathrm{b}}$ \\
\hline \multirow{2}{*}{ BOLORESE } & 0 & $3,45 \pm 0,64^{\mathrm{a}}$ & $3,45 \pm 0,64^{\mathrm{a}}$ & $3,45 \pm 0,64^{\mathrm{a}}$ \\
LEVEDURAS & 8 & $4,20 \pm 0,28^{\mathrm{a}}$ & $3,47 \pm 0,10^{\mathrm{a}}$ & $3,85 \pm 0,00^{\mathrm{a}}$ \\
& 16 & $4,33 \pm 0,18^{\mathrm{a}}$ & $4,15 \pm 0,11^{\mathrm{a}}$ & $4,10 \pm 0,03^{\mathrm{a}}$ \\
\hline
\end{tabular}

$\overline{\mathrm{a}, \mathrm{b}}$ letras diferentes na mesma linha indicam que houve diferença significativa ao nivel de 0,05 pelo teste de Tukey.

\section{5 - REFERÊNCIAS}

[1] AOAC Official methods of analysis. Association of Official Analytical Chemists, Washington D. C, 1984.

[2] APHA Compendium of methods for microbiological examination of foods. American Public Health Association, Washington, 1992.

[3] BENASSI, M.T.; ANTUNES, A.J.A. Comparison of metaphosphoric and oxalic acids as extractant solutions for the determination of vitamin $\mathrm{C}$ in selected vegetables. Arquivos de Biologia e Tecnologia, v.31, n.4, p.507513, 1988.

[4] BOUWAN, B.M.G.; LISBÔA, A.C.C.B. Fruticultura: uma opção de diversificação de propriedades. Revista Batavo, n.74, p.20-21, 1997.

[5] BRASIL. Portaria SVS/MS no 33, de 13 de janeiro de 1998. Tabelas de Ingestão Diária Recomendada (IDR). Diário Oficial da União de 16 de janeiro de 1998.

[6] COELHO, A.H.R. Qualidade pós-colheita de pêssegos. Informe Agropecuário, v.17, n.180, p.31-39, 1994.
[7] GARCIA, M.A.; MARTINO, M.N.; ZARITZKY, N.E. Starch-based coatings: effect on refrigerated strawberry (Fragaria $\mathrm{x}$ Ananassa) quality. Journal of the Science of Food and Agriculture, v.76, n.3, p.411-420, 1998.

[8] GONTARD, N; GUILBERT, S. Bio-packaging: technology and properties of edible and/or biodegradable material of agricultural origin. Boletim SBCTA, v.30, n.1, p.3-15, 1996.

[9] INSTITUTO ADOLFO LUTZ. Normas analíticas do Instituto Adolfo Lutz v.1. 2 ed. Instituto Adolfo Lutz, São Paulo, $1976.375 \mathrm{p}$.

[10] KELCO. Multi-functional polysaccharide for gelling and texturising. 3 ed. Monsanto Company, 1996.

[11] KESTER, J.J.; FENNEMA, O.R. Edible films and coatings: a review. Food Technology, v.40, n.12, p.47-59, 1986.

[12] KLUGE, R.A.; SCARPARE-FILHO, J.A.; JACOMINO, A.P.; MARQUES, C. Embalagens plásticas para pêssegos 'Flordaprince' refrigerados. Scientia Agricola, v.56, n.4, p.1-12, 1999.

[13] KROCHTA, J.M; MULDER-JOHNSTON, C. Edible films solve problems. Food Technology, v.51, n.2, p.60-74, 1997.

[14] LILL, R.E; O’DONOGHUE, E.M; KING, G.A. Postharvest physiology of peaches and nectarines. Horticultural Reviews, v.11, p.413-452, 1989.

[15] McHUGH, T.H; AUJARD, J.F; KROCHTA, J.M. Plasticized whey protein edible films: water vapor permeability properties. Journal of Food Science, v.59, n.2, p.416423, 1994.

[16] MINISTÉRIO DA SAÚDE. Portaria $\mathbf{n}^{\circ}$ 503: regulamentação da utilização da goma gelana. Disponivel em http:/ / www.cras.simpleweb.com.br/legisla/p503.htm.

[17] NAKASU, B.H; RASEIRA, M.C.B; CASTRO, L.A.S. Frutas de caroço: pêssego, nectarina e ameixa no Brasil. Informe Agropecuário, v.18, n.189, p.8, 1997.

[18] SECEX/MDIC (Secretaria de Comércio Exterior/Ministério do Desenvolvimento, Indústria e Comércio). Importações brasileiras de frutas. Disponível em http:// www.mdic.gov.br.

[19] STATSOFT. STATISTICA for Windows - Computer program manual. Statsoft Inc., Tulsa, 1995. 